\title{
Inquiry into the Permeation of Moral Education in Primary English Teaching
}

\author{
Qiutan Yu \\ Feixian Campus, Linyi University Linyi, Shandong, China \\ fxyuqiutan@126.com
}

\begin{abstract}
Moral education in English teaching refers to the moral education infusing in the process of the instruction of English language knowledge, the cultivation of English language and communicative ability in the way of permeation; it also refers that English teachers interpret and expound English teaching content with the connotation of moral education, combine various teaching methods which has the function of moral education permeation and emotion regulation of language teaching and set the pace of good teaching behavior, through which realizes the natural permeation of the content of moral education into instruction of English language knowledge achieve the purpose of training students' English language ability and communication ability, promoting students' moral awareness and cultivating moral emotion, moral will and moral behavior.
\end{abstract}

Keywords: Primary English teaching; Moral education; Permeation; Inquire.

\section{Embodiment of English Moral Education}

English is a Tool of Absorbing and Communicating Information which is Rich in Ideological Content . Language is a tool of thinking, also the main carrier of information and culture, which is the most important communication tool in human society and also one of the means of human survival and development. "Your words reflect your thinking." Any kinds of human language are the reflection of thoughts. No matter what kind of language units or language form contains certain ideological content. Words have meanings, and the same is true of phrases and passages. Every teacher adopting no matter what kinds of teaching ways, teaching methods and means will penetrate the general idea of English teaching, at the same time their own values and outlook on life, consciously or unconsciously infuse into the precept of the students, and the teachers' every talking is the expression of thought and understanding.

English, as a Communicative Tool of People's Development of Tool, is Practical. As a language, the characteristics of English have decided that it could not be instructed and learned mechanically. English teaching theory has sufficiently proved that although language can be learned, it should rather be truly acquired. Theory of language acquisition gives foreign language teaching enlightenment, that is, language as a tool to know the world, the vocabulary structure and semantic structure of a language reflects not only the language cognitive way to the world, but also the national history and cultural development trajectory, embodies that the culture tradition has the value orientation and other cultural information. For those language learners who have mastered the basic vocabulary and grammar structure of a language, their acquisition of semantic structure and foreign language vocabulary is bound to be affected by the native language and semantic knowledge. In addition, different nations have different ways of communication and the acquisition of discourse structure. That is to say, the acquisition and mastering of foreign language must be achieved through a large amount of concrete exercises and practice, while the contact and practice will be influenced unconsciously by mother tongue. So, in the process of practice, students will meet all kinds of problems and difficulties at any time, and at this time the teachers should give full play in leading, according to the specific situation of the students, mobilize their enthusiasm, exert their subjectivity, build up the confidence, cultivate their ability of independent, solve problems and guide them out of difficulties.

English, as an Aesthetic Beauty Tools, is Full of Sense of Beauty. As a language, English is an aesthetic object, which is embracing the beauty of connotation. There are all kinds of fine short and applicative articles in English textbooks, which contain many fields and many forms, some pleasing natural beauty, some inspiring moral beauty, some admiring dramatic artistic beauty, some wisdom- 
inspired scientific beauty, and some thought-provoking traditional and modern beauty, which is a colorful world of beauty. Teachers and students enjoy the sea of beauty with the aid of the language knowledge learning. The process of students' learning language knowledge, understanding, listening, speaking, reading and writing, skills' training is actually one of feeling, appreciation, expression and creation to beauty. Teachers can also give full play in its finding, supporting, publicity, contrasting, identifying and subliming beauty to achieve the education aim of "not only teaching knowledge but also educating people".

\section{Principles of Moral Education Permeation in English Teaching}

English moral principle refers to the principle and the law moral education. It is not only the application of general principles of moral education in English teaching, but also the reaction of special laws. In view of the characteristics of moral education in the primary English teaching and principles mentioned in pedagogy, I think the principles' permeation of moral education in primary English teaching are the followings.

The Principle of Moderation. Moral education permeation means conscious proliferation, migration and transfer of thoughts, sentiment and others to education objects to make them unwittingly accept. We should fully realize the dependency of the moral education permeation, prevent the far-fetched, formalism and labeling, organically combine the instruction of English knowledge with the ideological and political education in teaching, otherwise we will lose the essence of English teaching.

The Principle of Reality. Moral education in English teaching must pay attention to the reality of students. According to the students' psychological and physiological characteristics, practical ideology, mastering of knowledge and thinking development level, teachers should choose materials of moral education with planning and purpose, act according one's abilities and different individuals and adopt diversified teaching methods. Language teaching can't be replaced with ideological education, but integrate the ideological education into language teaching. Formalism would appear when out of reality, demanding too high and too urgent.

The Principle of Systematization. The formation of moral quality must experience a narrative, osmosis and gradual process. Therefore, moral education permeation in English teaching should follow the principle of education, running moral education through the whole course of teaching and learning and repeatedly penetrating its moral content to students without hoping in a certain class or content. Only persistence and perseverance of moral education in teaching can long-term edification and permeation receive the effect. English teachers should pay attention to the preparation of every English lesson and the process of teaching to design specific goal of moral education.

The Principle of Affection. Modern education psychology research shows that the process of a person's moral accomplishment and promotion is not primarily cognitive one, but emotional experience and influence culture process. Therefore, in English teaching, teachers should pay attention to the artistry and give full play to their roles as the emotional infection. Teachers' "appealing to emotion" can arouse students' response of love and make them be ready to learning English. Like "spring rain moistens everything silently", the word "Moisten" is most important. Teachers should integrate reasons into affection and combine them together to move people by affection, touch people by affection and educate people by affection. The integration of reason with affection in class makes teaching and learning have a harmonious resonance effect, and teachers should set an example with their words and actions. A good example is the best sermon. With strong career-ambition and high sense of responsibility, teachers should make the models for students with their words and actions, which would make moral education enter a new realm and get good education effect.

The Principle of Emphasis. There are a lot of teaching materials that can be used to carry out moral education permeation in English. Broadly speaking, every English lesson can and should conduct moral penetration, but in order to effectively improve the effect of moral education, should 
also follow the principle of emphasis, namely the lesson should highlight a major point of view, not trying to be well-round: the highlight of a key point should be powerful to obtain good effect.

\section{Strategies on the Implementation of Moral Education}

Meet the Demand of Students' Ability of Improvement and Comprehension. People have a natural resistance to demands in psychology, and students hope to have the freedom of choice, and don't be forced to participate in the activities they don't like. Therefore, teaching should return the right to students and give them enough right of decisions, allowing students to actively engage in learning activities, which put forward requirements to teachers: if there are varieties of activities which can realize a certain teaching goal, let students themselves decide the activity way; If possible, let the students decide classroom program arrangement; If possible, let the students decide the time, way and place of finishing their homework; give them enough sense of security in psychology; make them escape or ignore the ridicule and criticism of others; make them bold to making their own choice. If students behaviors should be restricted, teachers should give them reasonable explanation and express the acceptance of different opinions; allow students to review their own bad behavior and try not to punish; encourage them to formulate their own learning goals and make self-evaluation for their progress.

Improve Teacher's Teaching Strategy and Sublimate their Moral Education Ability. Education narration research is a kind of research being taken seriously in recent years and suitable for the first line teacher. Education narrative research refers to the education research carried out in the form of narrative, which is the meaningful description and analysis of the education teaching process mainly by teachers to discover or reveal the implicit education experience, thought and belief. The original meaning of narrative is telling the story, but narrative research brings narrative into a framework, which lead the teachers into research status.

Continuous summary of subject moral education practice is the only way to deepen and sublime subject moral education. According to the subject program of moral education, teachers should frequently retrospect those moral education practices, such as a practice, an attempt, a production, a design summary, to explore the rules of subject moral education in order to make them form regularity understandings, which are cases of subject moral education. After having accumulated a certain amount of cases, teachers have the conditions of further summary: from several induces a few classes, from a number generalizes regularity understanding of discipline curriculum moral education as a whole. Thus, exploration and practice step by step, teachers not only grasp the disciplines of moral education, but will have new discovery and creation, creating a unique brand of discipline curriculum moral education.

Perfect Moral Education Scheme and Improve its Effectiveness. Implementation of English subject moral education should avoid temporary permeation and develop a scientific and effective curriculum plan, which is a teaching action research integrated curriculum target, curriculum task, curriculum implementation, curriculum methods, curriculum evaluation and curriculum adjustment together. English curriculum design should put different kinds of moral education goals to the curriculum plan and arrange moral education factors in advance. If teachers combine these factors of moral education and practical teaching, the function of moral education can be achieved. Discipline moral education should be a conscious activity to practice and explore and a cognitive process; its development, design and configuration all have the need to constantly improve.

Teaching program of discipline moral education can be simple or complex. Take a measure of English moral education as an example, we can have tasks of multiple discipline moral education to compose and arrange. With a design program of moral education, the teacher will know what to do, where to do and what degree to do in the moral education in English teaching.

Carrying-out of Ethical Culture Teaching and Adjust Class Confliction. Subject moral education contains rich moral education resources, which needs English teachers have a pair of keen eyes to identify and find out where these resources are, what characteristics, which kind of property and how to effectively develop and so on. Teacher must have a clear understanding of the goals and tasks of 
subject moral education to achieve scientific development. Only teachers have clear and definite understanding of the subject moral responsibility will they base the analysis of English subject moral education resources on attentive discovery, flexible use and organic combination. Otherwise, the scientific exploitation will lose its psychological foundation and the moral education resources cannot give full play to the role.

\section{Summary}

Moral construction is a systematic project. As the saying goes, Rome was not built in a day. Youth ideological and moral education runs through adolescent growth and development process, involving all aspects of society. Different characteristics are shown at the different stages of the growth of the teenagers, which needs to plan as a whole. Therefore, we should speed up the study of the characteristics and laws of the development of contemporary youth growth, strengthen the systematic of ideological and moral education, pay special attention to the overall planning and develop the planned and systematic ideological and moral education of teenagers step by step. Youth's thoughts are easily affected by the environment, family, society and schools which are responsible for the formation of the ideology and ethics. Therefore, we should coordinate social various aspects of strength, make full use of all education channels and form joint force in the ideological and moral education of teenagers form. However, the core problem that school face is the moral education problem, and all other questions originate from it. In school education, teaching is the basic form, and classroom teaching is a central part of the accepted education. So, teaching is the main channel of moral education, and class is the main position of moral education. Teachers are the main force. Subject moral education permeation is bound to be a focus topic. Primary English teaching, as one of the important subjects, should help students understand western language knowledge, history and culture and mastering the language skills by teaching, and at the same time, strengthen the Chinese nation excellent traditional moral education, especially the patriotism education, let them know how to learn and respect the foreign excellent culture while love their motherland, set up the correct outlook on life and world view, really become builders and successors of our nation's future.

\section{References}

[1]. He Xiaowen. Exploration and practice of subject moral education[M]. East China normal university press.

[2]. Zhong Shengxiao. Affective communication teaching theory[M]. Nanjing Normal University Press. 2005.

[3]. Shen Yinzhen. Multicultural and modern English teaching[M] Hangzhou: Zhejiang University Press. 2006.

[4]. Zheng Jinzhou. Multicultural education[M]. Tianjin: Tianjin Education Press. 2004.

[5]. Wang Jiang, Wan Minggang. Multicultural education comparison research[M]. Beijing: Ethnic Publishing House. 2006.

[6]. Liu Runqing. English education research[M]. Beijing: Foreign Language Teaching and Research Press. 2004.

[7]. Liu Daoyi. Liu Daoyi English education essays[M]. Beijing: Foreign Language Teaching and Research Press. 2007.

[8]. Hu Wenzhong. Hu Wenzhong English education essays[M]. Beijing: Foreign Language Teaching and Research Press. 2005.

[9]. Wang Guoyin. Virtue ethics research[M]. Changchun: Jilin People's Publishing House. 2006:197.

[10]. Chen Zhanglong \& Zhou Li. Study of values[M]. Nanjing Normal University Press. 2004:69. 
[11]. Lu Jie. Moral education modernization practice research[M]. Nanjing: Jiangsu Education Press. 2003.11.

[12]. Banks J. A. Cultural diversity and education foundations, curriculum and teaching[M]. Boston: Allyn and Bacon. 2001.

[13]. Bennett C. Comprehensive multicultural education: theory and practice (2nded) [M]. Massachusetts: Allyn and Bacon. 1990. 